\title{
Orthodontic management of a case of Class III malocclusion with multiple unerupted teeth in both jaw \& retained deciduous teeth : A case report
}

\author{
Haque IE ${ }^{1}$ BDS, Faruq SMO ${ }^{2}$ BDS and Hossain MZ $^{3}$ BDS, PhD
}

\begin{abstract}
We describe the treatment of an adolescent girl, age 13 years old, with Class III malocclusion with multiple unerupted teeth in both jaw \& retained deciduous teeth. Treatment consists mainly of correction of anterior crossbite, extraction of deciduous teeth, surgical exposure of unerupted teeth \& orthodontic traction to help eruption, leveling and alignment with Edgewise fixed appliances with multiloop technique. Treatment time required 3years. However the treatment resulted in Class I molar occlusion with proper alignment of upper $\&$ lower anterior segment, an ideal overjet, overbite and incisor angulations.
\end{abstract}

Key Words: Class III malocclusion, cross bite, missing teeth, delayed eruption, edgewise orthodontic therapy (Bangladesh Journal of Orthodontics and Dentofacial Orthopedics, April 2013; Vol-3, No. 2, p 25-28)

\section{INTRODUCTION}

It is important for every orthodontist to have adequate knowledge \& correct understanding of the various types of Class III malocclusions before instituting a treatment plan. There is no universal method of managing the condition. ${ }^{1,2}$ It is essential to have an adequate knowledge of normal growth pattern \& various cephalometric analysis for proper diagnosis $\&$ treatment planning. ${ }^{3}$

Causes of delayed eruption are as follows ${ }^{4}$ :

- Cretinism

- Rickets

- Cleidocranial dysplasia

- Hereditary gingival fibromatosis

- Cherubism

- Down's syndrome

- Cerebral palsy

- Fetal alcohol syndrome

- Loss of space

- Abnormal position of crypt

- Dilaceration

- Overcrowding

- Supernumerary teeth \& odontome

- Dentigerous cyst

- Retention of deciduous predecessor.

- Early loss of deciduous tooth

- Arrested root development.

\section{CASE HISTORY}

Rifa, 13 years old, came to the Department of Orthodontics \& Dentofacial Orthopedics at Dhaka Dental College \& Hospital for treatment. The patient noticed with the advancing age,

delayed eruption of her permanent teeth in upper jaw\& deciduous teeth were still retained. Rifa was 9 years old when she first noticed prolong retention of deciduous teeth in both jaw. She went to a Dentist \& extracted some deciduous teeth. OPG was done at that time which shows multiple unerupted teeth. Now she suffers from aesthetic \& functional dysharmony and social embarrassment.

\section{CLINICAL EXAMINATION}

Figure-1 : Facial photographs

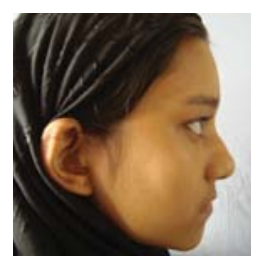

Right profile

Shape of the head

Profile Analysis

Shape of the face

Facial symmetry

Lips

Upper lip line

Lower lip line

Naso-labial angle

Labio-mental depression

Temporo-mandibular joint

Breathing

Deglutition

The patient was in permanent dentition but she presented with only upper central incisors, upper first molars, lower

${ }^{1}$ Dr. Imtiaz Ershadul Haque BDS, FCPS-II Trainee, Dept. of Orthodontics and Dentofacial Orthopedics, Dhaka Dental College and Hospital, ${ }^{2}$ Dr. S M Omar Faruk BDS, FCPS-II Trainee, Dept. of Orthodontics and Dentofacial Orthopedics, Dhaka Dental College and Hospital and ${ }^{3}$ Professor Dr. Md. Zakir Hossain, Professor and Head, Department of Orthodontics and Dentofacial Orthopedics, Dhaka Dental College and Hospital, Bangladesh. 
incisors, lower canines, lower 1st molar teeth and deciduous canine, molars at the age of 13 years. Molar \& incisor relationship was Class-III. Her oral hygiene was good.

Figure- 2 : Pre-treatment intraoral photographs
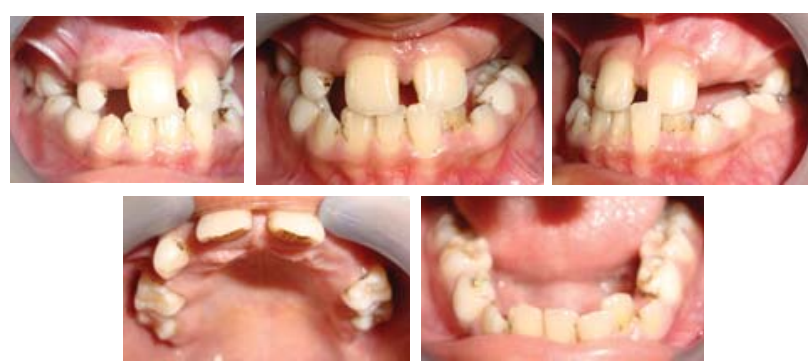

Fig-3: Pre-treatment photographs of models
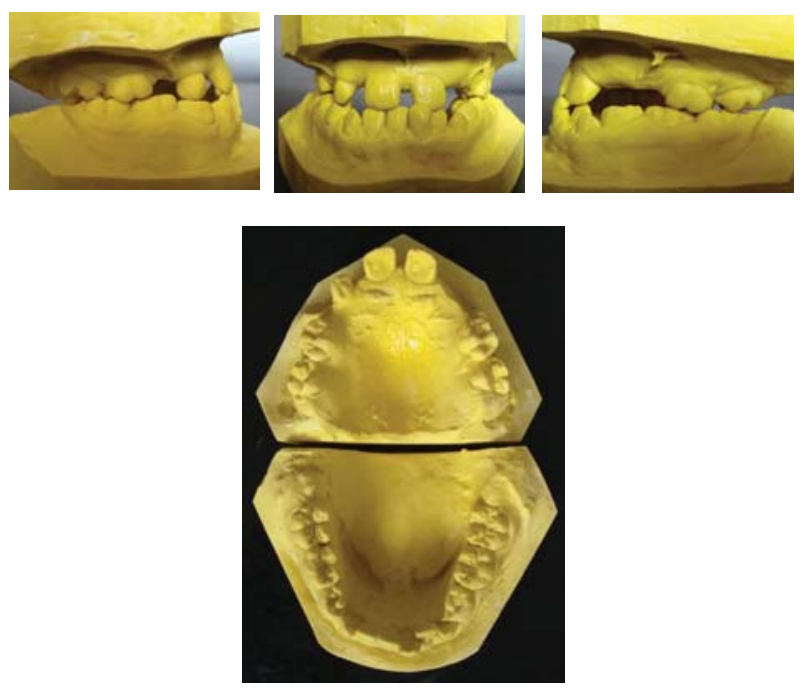

Figure-4 : Pre-treatment OPG.

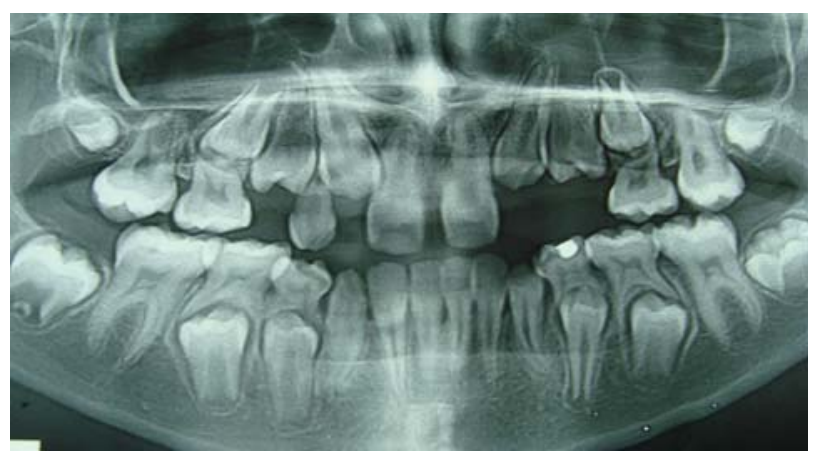

OPG shows all the permanent teeth except upper lateral incisors are present but canines and premolars are still unerupted and their apex still not closed.
Fig-5: pre-treatment lateral cephalogram and tracing

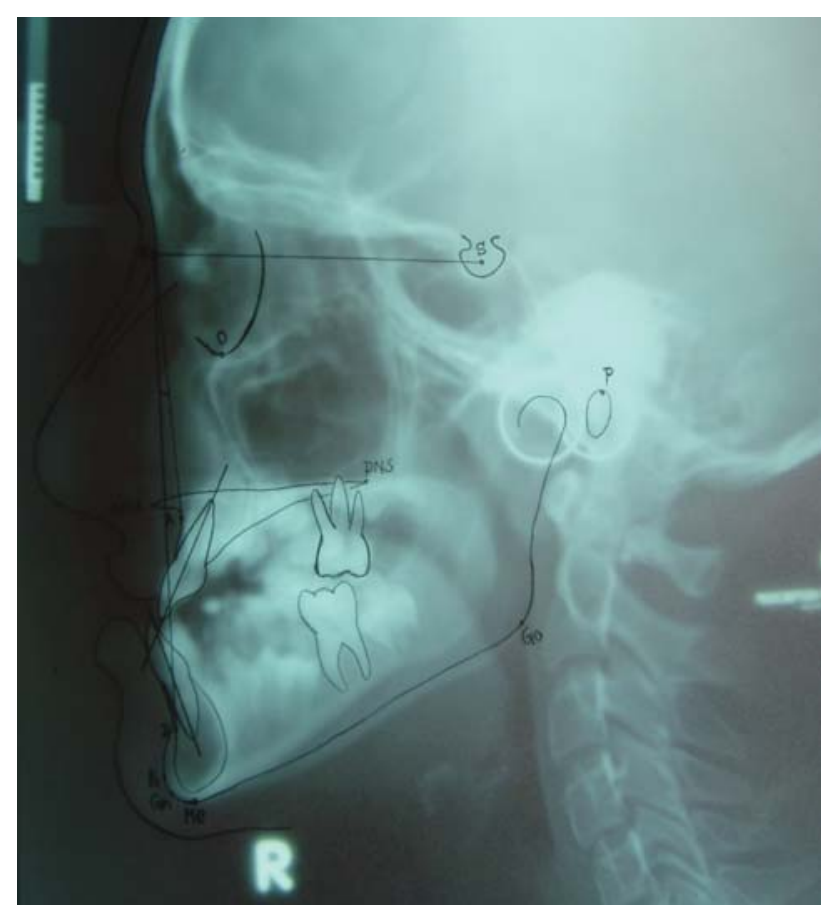

Table-1: Pre-treatment lateral cephalometric tracing results

\begin{tabular}{lcc}
\hline Parameter & $\begin{array}{c}\text { Reference } \\
\text { Measurement }\end{array}$ & $\begin{array}{c}\text { Patient's } \\
\text { Measurement }\end{array}$ \\
\hline SNA (angle) & $82^{\circ}$ & $83^{\circ}$ \\
SNB (angle) & $80^{\circ}$ & $87^{\circ}$ \\
ANB (angle) & $2^{\circ}$ & $4^{\circ}$ \\
Inter incisal angle & $131^{\circ}$ & $136^{\circ}$ \\
\hline
\end{tabular}

The analysis of lateral cephalogram revealed that the patient had a Class III skeletal base relationship due to mandibular prognathism

\section{AIM OF TREATMENT}

- Alignment \& levelling of unerupted teeth into occlusal plane.

- Correction of incisor relationship

- Establishment of normal inter-incisal angle \& molar relation.

\section{TREATMENT PLAN}

Stage 1: URA with modified palatal finger spring to correct the anterior crossbite \& approximation of upper central incisors. 
Stage 2: Extraction of all the deciduous teeth \& wait for eruption of permanent teeth.

Stage 3: Surgical exposure \& orthodontic traction to help eruption of unerupted teeth.

- Leveling and alignment

- Up down elastics to correct the lateral open bite.

- Prosthesis to fill up the missing teeth spaces.

Fig-6: During treatment photographs

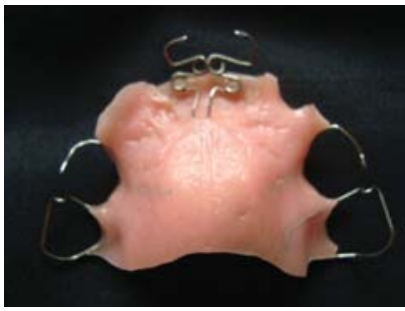

URA

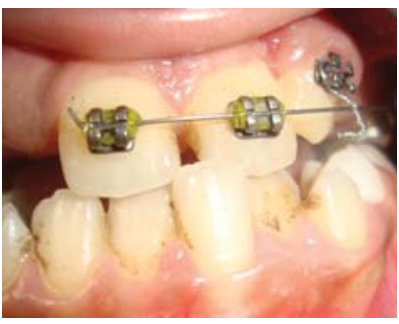

Orthodontic traction

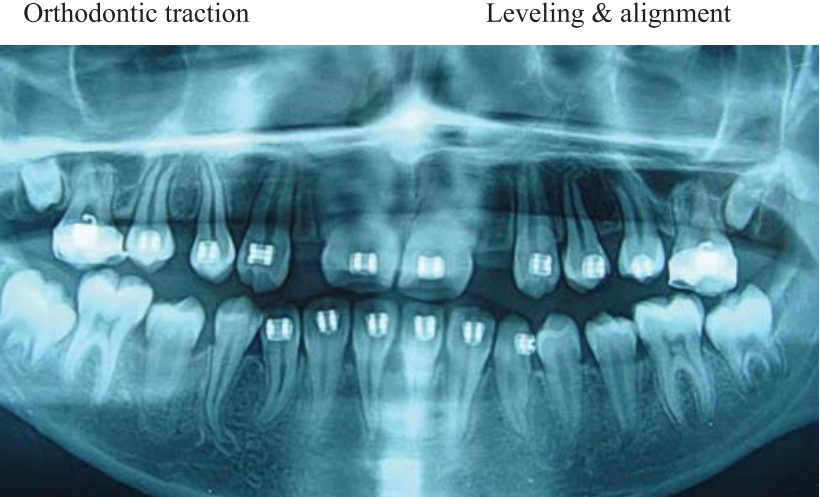

During treatment OPG
Figure-7 : Post treatment Intraoral photographs
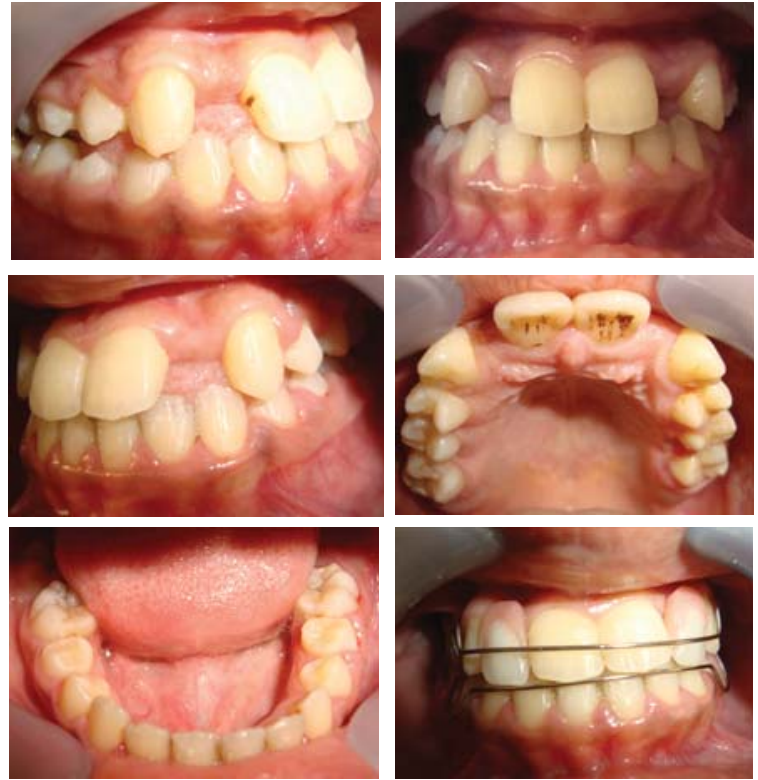

Fig-8: Post treatment extra oral photographs
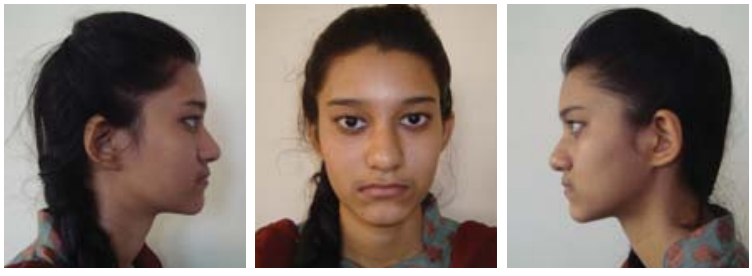

Fig-9 : post treatment OPG

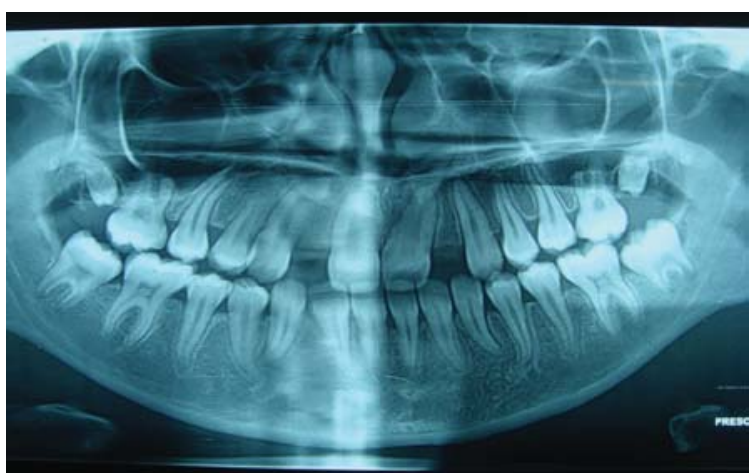


Fig - 10 : post treatment lateral cephalogram

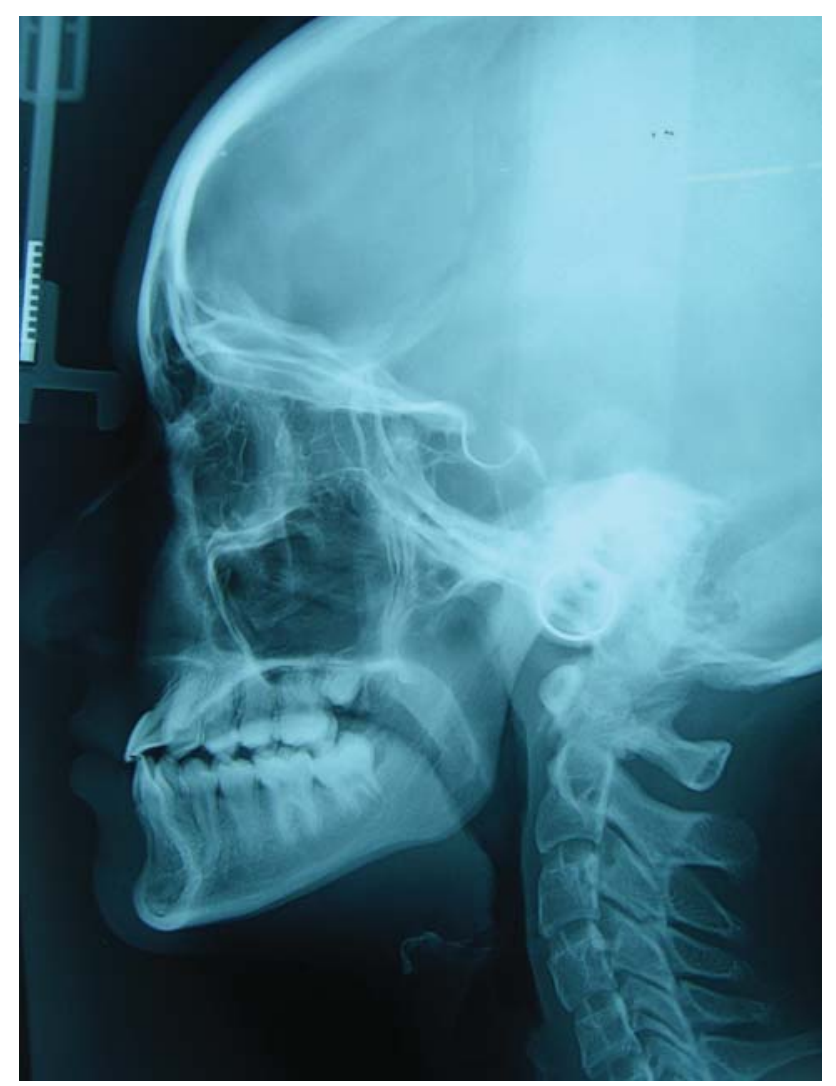

\section{DISCUSSION}

One of the most common problems in orthodontics today is Class III malocclusion. Treatment is more complicated when unerupted or missing teeth persist . This patient was treated with upper removable appliance at first, extraction of retained deciduous teeth and light orthodontic forces to produce a result that was pleasing to the patient and satisfying to the orthodontists in 3 years period. At retention stage we incorporated two lateral incisor teeth to the upper removable retainer for aesthetic and functional purpose and advised to prosthesis of lateral incisors.

\section{CONCLUSION}

Analysis of final records indicated that all treatment objectives were achieved. The teeth were placed in good alignment, anterior cross bite were relieved \& good occlusion was maintained. A satisfactory esthetic result had been achieved. The parent \& patients psychological satisfaction was also achieved.

\section{REFERENCES:}

1. Singh G. Classification of malocclusion: Textbook of Orthodontics. 2nd ed. 159-174, 2007.

2. Tweed, C. H.: Indications for the extraction of teeth in orthodontic procedure, AM. J. ORTHOD. ORAL SURG. 30: 405-428, 1944.

3. Proffit WR. Fields H W. , Contemporary Orthodontics. 4th ed. St Louis; Mosby; 2001.

4. Essentials of Oral pathology \& oral medicine by R.A. Cawson, E.W. Odell, 6th edition.

Correspondence

Dr. Imtiaz Ershadul Haque BDS

FCPS-II Trainee

Dept. of Orthodontics and Dentofacial Orthopedics

Dhaka dental College and Hospital

Mirpur-14, Dhaka-1206

Mobile: +8801712277956

E-mail : anjanex@yahoo.com 